CDD: 027.4

\title{
PERFIL TECNOLÓGICO DAS BIBLIOTECAS PÚBLICAS NO BRASIL E NA EUROPA: ESTUDO SOBRE A DEMOCRATIZAÇÃO DO ACESSO À INFORMAÇÃO E AO CONHECIMENTO EM BIBLIOTECAS DO BRASIL, ESPANHA E ALEMANHA
}

\author{
TECHNOLOGICAL PROFILE OF PUBLIC LIBRARIES IN BRAZIL AND EUROPE: \\ A STUDY ON DEMOCRATIZATION OF ACCESS TO INFORMATION AND \\ KNOWLEDGE IN LIBRARIES IN BRAZIL, SPAIN AND GERMANY

\section{Maria Cleide Rodrigues Bernardino ${ }^{1}$ Eduardo da Silva Alentejo ${ }^{2}$}

Resumo: A biblioteca pública é uma instituição que se fundamenta por sua forte função social, que por sua vez encontra amparo nos desdobramentos educativos, culturais, econômicos e políticos, em observância ao Manifesto da UNESCO que determina que a mesma seja um centro local de informação prontamente acessível a todos os seus usuários em qualquer suporte ou gênero, porta de acesso local ao conhecimento. Para o êxito dessa função na sociedade da informação faz-se necessário o uso e a manipulação de tecnologias digitais. Esta investigação se dá no âmbito brasileiro, espanhol e alemão, com um recorte para a utilização de mídias digitais de democratização da informação, que permitam o acesso à informação, como direito básico do cidadão na sociedade da informação. A pesquisa de cunho exploratório e delineamento quali-quantitativo utiliza-se do instrumento questionário enviado por correio eletrônico e análise do discurso para a avaliação dos dados coletados. Neste sentido, será traçado um perfil tecnológico da biblioteca pública na Europa e no Brasil a fim de delinear os encaminhamentos para a sociedade da informação.

Palavras-chave: Biblioteca Pública. Sociedade da Informação. Tecnologias da Informação. Inclusão Digital.

\begin{abstract}
The public library is an institution that is based on its strong social function, which in turn finds support in educational, cultural, economical and political developments, in compliance with the UNESCO Manifesto, which states that the library is a local center of information readily accessible to all its users in any medium or genre. It is the local gateway to knowledge. For the success of this function in the information society it is necessary the use and manipulation of digital technologies. This research is done within Brazilian, Spanish and German environment, with a cutout for the use of digital media in the democratization of information, which allows the access to information as a basic right of citizens in the information society. The research has an exploratory design with qualitative and quantitative outline. It also uses questionnaires (sent by e-mail) as instrument, and discourse analysis for the evaluation of the collected data. In this sense, a technological profile of the public library

\footnotetext{
${ }^{1}$ Universidade Federal do Ceará/Campus Cariri. Professora Assistente do Curso de Biblioteconomia da Universidade Federal do Ceará, Campus Cariri. Brasil. E-mail: cleide@ @ariri.ufc.br

${ }^{2}$ Universidade Federal do Estado do Rio de Janeiro - UNIRIO. Professor Assistente do Curso de Biblioteconomia da UNIRIO. Brasil. E-mail: alenteju@ gmail.com
} 
in Europe and Brazil will be traced in order to delineate the referrals to the information society.

Key-words: Public Library, Information Society, Information Technology, Digital Inclusion.

\section{INTRODUÇÃO}

As atuais concepções sobre bibliotecas públicas ganham cada vez mais força na sociedade, impulsionadas pelas recentes transformações sociais e tecnológicas nas últimas décadas em nível global, tais como: a consolidação do regime democrático e o advento das tecnologias da informação e da comunicação.

Nesse processo, a biblioteca tem se tornado uma instituição democrática, de fonte universal de acesso à informação e de socialização do conhecimento dentro do que se convencionou ser chamado de Sociedade da Informação. E, tal como explica Lankes (2011), a missão dos bibliotecários é melhorar a sociedade, facilitando a criação de conhecimento em suas comunidades.

Isso não é simplesmente pelo fato de ser intrínseco às suas funções na sociedade, mas, sobretudo, pelas mudanças na dinâmica do acesso à informação, consequências da sociedade da informação. Neste sentido, conforme afirmam Jaramillo, Montoya Rios e Uribe Tirado (2008, p. 9, tradução nossa) a concepção de biblioteca pública está diretamente "relacionada com o direito à informação, com a educação, a recreação e a cultura" e, portanto, está "fundamentada no acesso livre e gratuito a informação, independentes dos suportes e formatos em que se encontrem".

A Garantia ao livre acesso à informação e dispô-la em qualquer suporte em que ela se encontre requer que a biblioteca pública esteja equipada tecnologicamente, disponha de acesso em rede à Internet e que seus funcionários saibam manipular as ferramentas informacionais e os meios de busca e recuperação da informação. Esta é uma questão política que na maioria das vezes embarga toda e qualquer iniciativa no sentido de garantir aos usuários seus direitos e atuar em consonância com os ditames da sociedade da informação.

Esta investigação é uma pesquisa exploratória, com delineamento qualiquantitativa. $\mathrm{O}$ instrumento utilizado é o questionário que foi enviado por correio eletrônico às bibliotecas públicas relacionadas no estudo. A avaliação e a tabulação dos resultados qualitativos deram-se pela análise do discurso da escola francesa, que é 
descrita por Foucault (2005, p. 133) como um conjunto de enunciados que se apoia em uma formação discursiva que é "constituído de um número limitado de enunciados para os quais podemos definir um conjunto de condições de existência”, o que significa analisar as construções ideológicas de um texto.

O objetivo dessa investigação é quantificar as mídias digitais e aparatos tecnológicos disponíveis nas bibliotecas públicas em estudo e determinar por meio das narrativas discursivas questões relativas à conectividade e à interatividade fundamentais para facilitar o acesso a informação na sociedade da informação.

Por fim buscaremos traçar um perfil tecnológico das bibliotecas estudas a fim de analisar questões relacionadas ao acesso à informação na sociedade da informação, tendo como parâmetro as bibliotecas públicas do Brasil e da Europa, configuradas aqui pela Espanha e Alemanha especificamente. A escolha dessas bibliotecas deveuse a facilidade dos autores, tendo em vista, a realização de estágio doutoral nestes países e o interesse pela temática.

\section{A BIBLIOTECA PÚBLICA MISSÃo E FUNÇÕES NO ÂMBITO DA SOCIEDADE DA INFORMAÇÃO}

A biblioteca pública é pautada por funções que auxiliam no direcionamento de suas atividades e atuação, as quais devem ser de acordo com as necessidades da comunidade usuária. É importante salientar que, diante da missão da biblioteca pública de se constituir em porta para o conhecimento o seu papel para com a sociedade da informação adquire um desenho administrativo e gerencial que passa pelas tecnologias, formação profissional e responsabilidade social. O que significa que na sociedade da informação, o papel das bibliotecas públicas deverá destacar o acesso à informação como prioridade, o que por sua vez implica em compreender sua missão e funções na sociedade e um gerenciamento proativo e dinâmico.

Muitos autores enumeram as funções da biblioteca pública e sua missão, entretanto, alguns dão destaque somente a função social, que apesar de ser primordial, não está isolada e necessita de um encadeamento de ações para obter êxito. Jaramillo, Montoya Rios e Uribe Tirado (2008) destacam três funções para a biblioteca pública e seus desdobramentos: as funções sociais, as funções técnico - tecnológicas e as funções administrativas. A visão dos autores supracitados se aproxima do nosso 
entendimento no que diz respeito ao delineamento das ações e responsabilidades da biblioteca pública na sociedade da informação em acordo com suas funções nesta sociedade.

Jaramillo, Montoya Rios e Uribe Tirado (2008) assinalam que as funções sociais da biblioteca pública se relacionam com as ações educativas, política, econômica e cultural com as quais a biblioteca pública responde às demandas informacionais da comunidade e que suas ações devem centrar-se sobremaneira, no livre acesso à informação.

Dessa forma, fazem parte das funções sociais: a) a função educativa: que permite facilitar e proporcionar à comunidade usuários, os meios e materiais para a educação e autoeducação. Esta função se relaciona diretamente com o que diz o Manifesto da IFLA/UNESCO sobre bibliotecas públicas (INTERNATIONAL FEDERATION OF LIBRARY ASSOCIATIONS; UNITED NATION EDUCATIONAL, 1994) quanto a apoiar programas formais e informais de educação inclusive de alfabetização; b) a função cultural: cujo objetivo é se converter em espaço de difusão e propagação de cultura, para gerar, resgatar, preservar os valores e a identidade cultural da comunidade usuária. Esta função prevê a participação ativa da sociedade seja na apreciação das expressões artísticas e culturais seja na execução dessas performances; c) a função econômica: diz respeito à responsabilidade da biblioteca no fornecimento de informações relevantes para o desenvolvimento econômico da comunidade, como por exemplo, o apoio à ações de cadeias produtivas, que contribui para a geração de renda e melhoria da qualidade de vida de comunidades; d) e a função política: de fundamental importância para o desenvolvimento das atividades da biblioteca pública, uma vez em que apoia a participação consciente e ativa na política da sociedade que será responsável por diversas ações futuras e permite a efetivação de relações da biblioteca com a sua comunidade.

Já as funções técnico-tecnológicas se relacionam com os processos e técnicas do trabalho biblioteconômico e assinala as possibilidades de êxito para as funções sociais. Estas funções estão ligadas às atividades de a) coleta: política de formação de acervo, seleção, aquisição e avaliação; b) análise e organização: processos técnicos 
utilizados como catalogação, classificação e indexação; e c) difusão e promoção: ligados à extensão e serviços.

As funções administrativas enumeradas por Jaramillo, Montoya Rios e Uribe Tirado (2008) diz respeito à visão gerencial e aos processos de planejamento, execução e controle. No âmbito da sociedade da informação as três funções se encadeiam e entrelaçam em acordo com a própria missão da biblioteca pública perante às inovações tecnológicas e demandas da sociedade do conhecimento. Felicié Soto (2006) postula que a missão fundamental da biblioteca pública é proporcionar aceso livre e gratuito à informação a todas as pessoas da comunidade. Sobre isto, o Manifesto da IFLA/UNESCO sobre bibliotecas públicas (1994) postula que a liberdade, a prosperidade e o desenvolvimento da sociedade e das pessoas são valores fundamentais e que para alcança-los os cidadãos devem ter seu direito à informação assegurado.

Neste sentido, para assegurar o direito ao acesso à informação, o respeito às funções da biblioteca pública e o pleno funcionamento na sociedade da informação é necessário que a biblioteca se reconheça como instituição impar para o exercício da cidadania de sua comunidade. É preciso, conforme orienta Suaiden (2002, p. 333) que a biblioteca se projete para a comunidade e assuma "seu papel legítimo no ensino, educação e formação e divulgação dos recursos culturais do país".

\subsection{Biblioteca Pública: porta aberta para o conhecimento}

Como instituição democrática e de funções marcadamente social, cultural e educacional a biblioteca pública tem os pressupostos para desempenhar com sabedoria e responsabilidade social seu papel na sociedade da informação. O Manifesto da UNESCO, que afirma que, a biblioteca pública é,

o centro local de informação, disponibilizando prontamente para os usuários todo tipo de conhecimento. Os serviços fornecidos pela biblioteca pública baseiam-se na igualdade de acesso para todos, independentemente de idade, raça, sexo, religião, nacionalidade, língua, status social (INTERNATIONAL FEDERATION OF LIBRARY ASSOCIATIONS; UNITED NATION EDUCATIONAL, 1994). 
Esta diretriz coloca a biblioteca pública em choque com suas debilidades, uma vez em que esta reforça coloca o papel da biblioteca pública perante a sociedade da informação e frente a uma responsabilidade de garantir o direito à informação a todos que dela necessitem. Isto por sua vez evidencia algumas fraquezas no âmbito tecnológico e profissional e exige uma ação mais efetiva em relação ao envolvimento nas funções política e econômica da instituição. Questões como a desigualdade social e a exclusão digital, ainda frequentes na sociedade, afastam cada vez mais a biblioteca pública de desempenhar seu papel perante a sociedade da informação.

O volume de informação cresce assustadoramente a cada minuto, as tecnologias cada vez mais modernas e interativas "permitem o acesso fácil, rápido e eficiente a uma grande variedade de conteúdos" (FELICIÉ SOTO, 2006, p. 41) que contribuem para a geração de conhecimento. Entretanto, a biblioteca pública tendo em vista sua estrutura administrativa por muitas vezes demora em adquirir os equipamentos necessários, programas e aplicativos para lograr o acesso universal a informação. Este é o que Lozano Díaz (2006) denomina de paradigma burocrático tradicional, que impede a biblioteca pública de se desenvolver na mesma proporção que se desenvolvem as tecnologias e a internet.

Ao mesmo tempo em que a internet é uma realidade, as desigualdades sociais, políticas e econômicas também são. A exclusão digital, a falta de acesso físico às tecnologias ou a falta de conhecimento necessário para manipular essas tecnologias afastam ainda mais a biblioteca pública do direcionamento e observância de sua missão, como porta aberta para o conhecimento. Ou seja, todo o tipo de conhecimento em qualquer formato ou suporte.

Cunha et al (2005, p. 3) constatam que:

A Sociedade da Informação por um lado aproxima pessoas, organizações, ideias e conhecimento e, por outro, cria um fosso entre as camadas que têm acesso à informação e ao uso dos espaços com produtos e serviços de informação, incluindo acesso à Internet e os desprovidos dessa condição.

Esse fosso que os autores denunciam é o que se denomina por exclusão digital, que mesmo em países considerados de primeiro mundo como a Espanha e a Alemanha são observadas ainda em escala destoante dos investimentos em Educação 
e Tecnologia desses países, originada pela distribuição do Produto Interno Bruto (PIB).

Diante disso, a biblioteca pública é o espaço ideal para que a comunidade tenha acesso a informação em respeito às diretrizes da Federação Internacional de Associações e Instituições Bibliotecárias (IFLA) / UNESCO e a missão norteadora da biblioteca pública. Entretanto, a instituição encontra algumas barreiras neste sentido, além dos entraves oriundos do avanço crescente das tecnologias de informação, a problemática social, costumes e até mesmo aspectos relativos à violência, afastam a comunidade da biblioteca. É preciso estabelecer e fortalecer os vínculos da biblioteca pública com a comunidade. Em contrapartida, a comunidade precisa se ver fazendo parte da biblioteca. Felicié Soto (2006, p. 111, tradução nossa) afirma que além de "cumprir com suas responsabilidades tradicionais, a biblioteca deve-se constituir em uma entidade que tenha presença vigorosa na vida da comunidade".

Esse vínculo com a comunidade dá-se em consequência do cumprimento de suas três funções, de um envolvimento intrínseco com a sociedade, do estabelecimento de relações políticas e culturais e, sobretudo, na constituição de espaços democráticos de reflexão e discussão de ideias para a geração de conhecimento. Sobre isto Bernardino e Suaiden (2011, p. 39) afirmam que,

Em seu Manifesto sobre a Biblioteca Pública, a UNESCO destaca que a mesma deve servir como fonte de reflexão sobre seu papel e suas funções, assim, as bibliotecas públicas devem estimular os leitores para a reflexão das informações processadas, garantindo com isso que possam interagir mentalmente e construir conhecimento.

A garantia de que a biblioteca pública é uma porta aberta para o conhecimento é dada pelo direito à informação de cada cidadão, cada leitor. Entretanto, ainda há muito que avançar no sentido de garantir esse direito básico da comunidade usuária, uma vez em que constata-se que a "biblioteca pública atual segue com poucas transformações, o modelo herdado das bibliotecas do Século XIX” (LOZANO DÍAZ, 2006, p. 22, tradução nossa). Assim, mesmo seguindo a passos lentos, as bibliotecas enfrentaram transformações ao longo da história, mudanças pontuais que repercutem diretamente em seus serviços, como o impacto da internet e o avanço das tecnologias 
da informação. A concepção da biblioteca pública como lugar de integração é um dos desafios para a sociedade da informação.

\subsection{Diretrizes para Bibliotecas Públicas na Sociedade da Informação}

Quando falamos em acesso à informação devemos ter em mente que a informação registrada, seja em qualquer suporte ou formato, deve estar disponibilizada a todos que dela necessitem. Quando falamos em acesso a informação na biblioteca pública, falamos também de aparato tecnológico que permita a recuperação rápida e gratuita. Falamos ainda de que nesta biblioteca não pode haver censura de qualquer espécie ou razão.

A democratização do conhecimento a partir do acesso a informação registradas em meio físico ou digital e veiculadas tradicional ou eletronicamente ao mesmo tempo em que é um direito do cidadão é também uma premissa da biblioteca pública. Para tal faz-se necessário uma estrutura de informação, correspondendo aos equipamentos físicos, programas e aplicativos, e formação profissional.

O reconhecimento da biblioteca pública como espaço propício ao exercício da cidadania não é algo novo ou inédito. Cuevas Cerveró (2009, p. 201, tradução nossa) afirma que "dentre todas as bibliotecas existentes, as bibliotecas públicas se sobressaem por sua contribuição quanto a materialização dos direitos constitucionais dos cidadãos". Essa preocupação com o caráter democrático da biblioteca pública foi tema de discussão em 1999, quando da Declaração de Copenhague, que debate o papel e as funções da biblioteca pública na sociedade da informação (DIAZ SANCHÉZ, 2008). Na ocasião foi dado um destaque especial a responsabilidade social da biblioteca pública na alfabetização informacional e a educação permanente. Algo antes pensado pelo Manifesto da IFLA/UNESCO sobre bibliotecas públicas (1994), ampliado para as questões de competência informacional do usuário.

Sendo a biblioteca pública o lugar que se efetivará a construção da cidadania e onde o usuário acessará a informação de forma eficiente e efetiva, usará a informação com precisão e criatividade e avaliará essa informação de forma critica e consciente. A discussão do papel da biblioteca pública é retomada em 2003, com o Manifesto de Oeiras, aprovado na Conferência Europeia PULMAN ${ }^{3}$, que definiu um plano de ação

\footnotetext{
${ }^{3}$ Europe's network of excellence for public libraries, museums and archives
}

\begin{tabular}{l|l|l|l|l|l|l|}
\hline (C) Rev. digit. bibliotecon. cienc. inf. & Campinas, SP & v.11 & n.3 & p.46-71 & set./dez. 2013 & ISSN 1678-765X \\
\hline
\end{tabular}


com objetivos e metas para bibliotecas públicas, museus e arquivos (DÍAZ SANCHES, 2008).

Em 2005 é lançado o Manifesto de Alexandria ${ }^{4}$ para bibliotecas na sociedade da informação, onde é anunciado o papel fundamental das bibliotecas para a construção de uma sociedade da informação aberta e democrática. O Manifesto destaca ainda a importância das bibliotecas no combate a exclusão digital e sua inserção na economia mundial. Pois conforme aponta Suaiden (2002, p. 336, tradução nossa)

“[...] em uma sociedade da informação, produção de conhecimento gera riqueza, muitas vezes na forma de patentes, assim consolidando a hegemonia de países desenvolvidos [...]".

Objetivo desses documentos é traçar diretrizes que encaminhem a biblioteca pública para atuar de forma eficiente na sociedade da informação. Como afirma Suaiden (2000), a sociedade da informação traz consigo aspectos relacionados a globalização, tecnologias e desenvolvimento sustentável. Esses aspectos se intermediam nas relações que estabelecem com o usuário e a biblioteca e por sua vez trazem consigo aspectos de acesso e direito à informação.

A biblioteca pública neste sentido ocupa uma posição de busca e conquista do seu espaço quanto à democratização do direito à informação, o acesso e a necessidade de "assumir um caráter efetivo na vida das pessoas", (CAVALCANTE, 2010, p. 6) tornar-se útil, estabelecer uma vinculação e interação com a comunidade usuária. Esse caráter efetivo está ligado ao envolvimento com a comunidade no âmbito político, econômico, cultural, educacional e social.

A atuação da biblioteca pública na sociedade da informação é evidenciada por Cunha (2003, p.72) quando afirma que,

A sociedade da informação, nos diferentes espaços geográficos em que vem sendo concebida, atribui à biblioteca pública a missão especial de assegurar a democratização do acesso em rede, a oferta de produtos e serviços de qualidade que contribuam para diminuir as desigualdades

\footnotetext{
${ }^{4}$ Disponível em: http://rcbp.dglb.pt/pt/ServProf/Documentacao/Paginas/Manifestos.aspx
} 
sociais e estimular os usuários a utilizar a internet como instrumento de ampliação de conhecimento e convivência [...]

Assegurar a democratização do acesso à informação em rede e com isto diminuir as desigualdades sociais não é pouca coisa. Entretanto, para que isto se configure em realidade é preciso um reconhecimento das autoridades governamentais, é preciso um estabelecimento de políticas públicas de Estado que garantam as condições de atuação de todas as bibliotecas públicas nesta sociedade da informação. Todas as bibliotecas incluem realmente todas que houver em um pais, independente se está situada em um grande centro ou em um pais de terceiro mundo.

\section{PROCEDIMENTOS METODOLÓGICOS}

A pesquisa é a atividade básica da ciência para a construção da realidade e geração de conhecimento. Para Minayo (2008) metodologia da pesquisa é o caminho do pensamento a ser seguido e ocupa um lugar de destaque na teoria e pode ser descrita como o conjunto de técnicas a ser adotada para construir uma realidade. Esta investigação trata-se de uma pesquisa exploratória que permite um estudo preliminar com o objetivo de compreender o fenômeno (GIL, 1999).

A abordagem utilizada é quali - quantitativa uma vez que uma completará a outra e por fim será feito uma triangulação metodológica que permitirá a avaliação dos dados coletados no questionário (MINAYO, 2008). Defendemos a escolha das abordagens quantitativas e qualitativas, uma vez que é nosso entendimento que essas abordagens não se opõem ou se contradizem, mas, sobretudo, se complementam (MINAYO, 2008).

Para a coleta de dados foi utilizado questionário aberto e fechado com a finalidade de determinar a partir dos discursos questões relativas a conectividade e interatividade nas bibliotecas e quantificar o material tecnológico disponível. Para assegurar a análise qualitativa usaremos a análise do discurso francesa.

A proposta para uma discussão do objeto discurso foi introduzida por Pêcheux (1995) cujo objetivo era produzir um espaço para a reflexão da prática das ciências sociais na época, que para ele era elitizada e isolada e tratava-se de um confronto das ciências como espaço de discussão e compreensão da sua essência. Pêcheux (1995) 
chamava a isto de entremeio, mas o objeto estudado era o discurso. Mais tarde Foucault (2005) introduziria o termo discurso e interdiscurso para analisar as condições ideológicas contidas no discurso a partir de construções semânticas que permitem analisar o não dito no dito.

\section{ANÁLISE DOS RESULTADOS}

Apresentamos a seguir a análise dos dados coletados através de survey com perguntas abertas e fechadas e enviado por correio eletrônico para todas as bibliotecas públicas do Sistema Nacional de Bibliotecas Públicas (SNBP/RJ) do Brasil, para a Red de Bibliotecas Públicas da Espanha e para a Bibliothek \& Information Deustshland (BID), na Alemanha.

O questionário constava de sete perguntas, sendo quatro fechadas e três abertas contemplando questões relacionadas ao acesso à informação e às tecnologias de informação e comunicação a fim de revelar um perfil tecnológico propício para viabilizar o acesso a toda e qualquer informação na biblioteca. Obtivemos 22 retornos das bibliotecas públicas da Espanha, 2 da Alemanha e 52 do Brasil. Para assegurarmos o sigilo da pesquisa para cada biblioteca respondente atribuímos a designação BPE (Biblioteca Pública da Espanha); BPA (Biblioteca Pública da Alemanha) e BPB (Biblioteca Pública do Brasil) e numeramos progressivamente.

\subsection{Acesso à Informação em Bibliotecas Públicas da Espanha}

Ao perguntarmos sobre a adequação de acesso às tecnologias nas bibliotecas da Red de Bibliotecas Públicas da Espanha 4\% apontam que acesso à tecnologia na biblioteca é ruim e 36\% apontam que o acesso é regular, prejudicado pela falta de assistência tecnológica adequada à manutenção e atualização dos recursos na biblioteca. Já 55\% apontam que o acesso à tecnologia na biblioteca é satisfatório e apenas 5\% afirmam que o acesso é excelente. Conforme demonstra o Gráfico 1: 


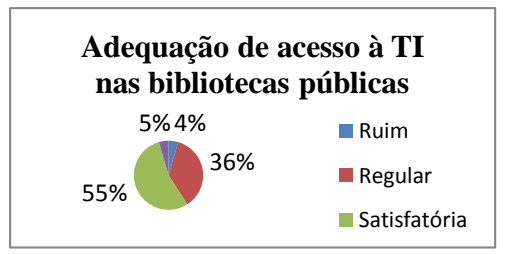

GRÁFICO 1. Adequação de acesso à tecnologia nas bibliotecas públicas - Espanha

No que diz respeito aos recursos tecnológicos oferecidos aos usuários $100 \%$ das bibliotecas respondentes possuem as ferramentas tecnológicas necessárias e 90,9\% possuem serviços de acesso à informação para os usuários, incluindo acesso ao portal da biblioteca. Quanto ao acesso aos serviços 95,5\% possuem catálogo online com serviços de informação, destes apenas $50 \%$ oferecem serviços online de empréstimo de documentos, tendo $82 \%$ de possibilidades de contatos e atendimentos através de e-mail com o usuário. Já os recursos de acesso às fontes externas de informação como acesso aos hiperlinks, bases de dados e redes sociais somam 22,7\%, $59,1 \%$ e $30 \%$ respectivamente, conforme podemos visualizar no Gráfico 2:

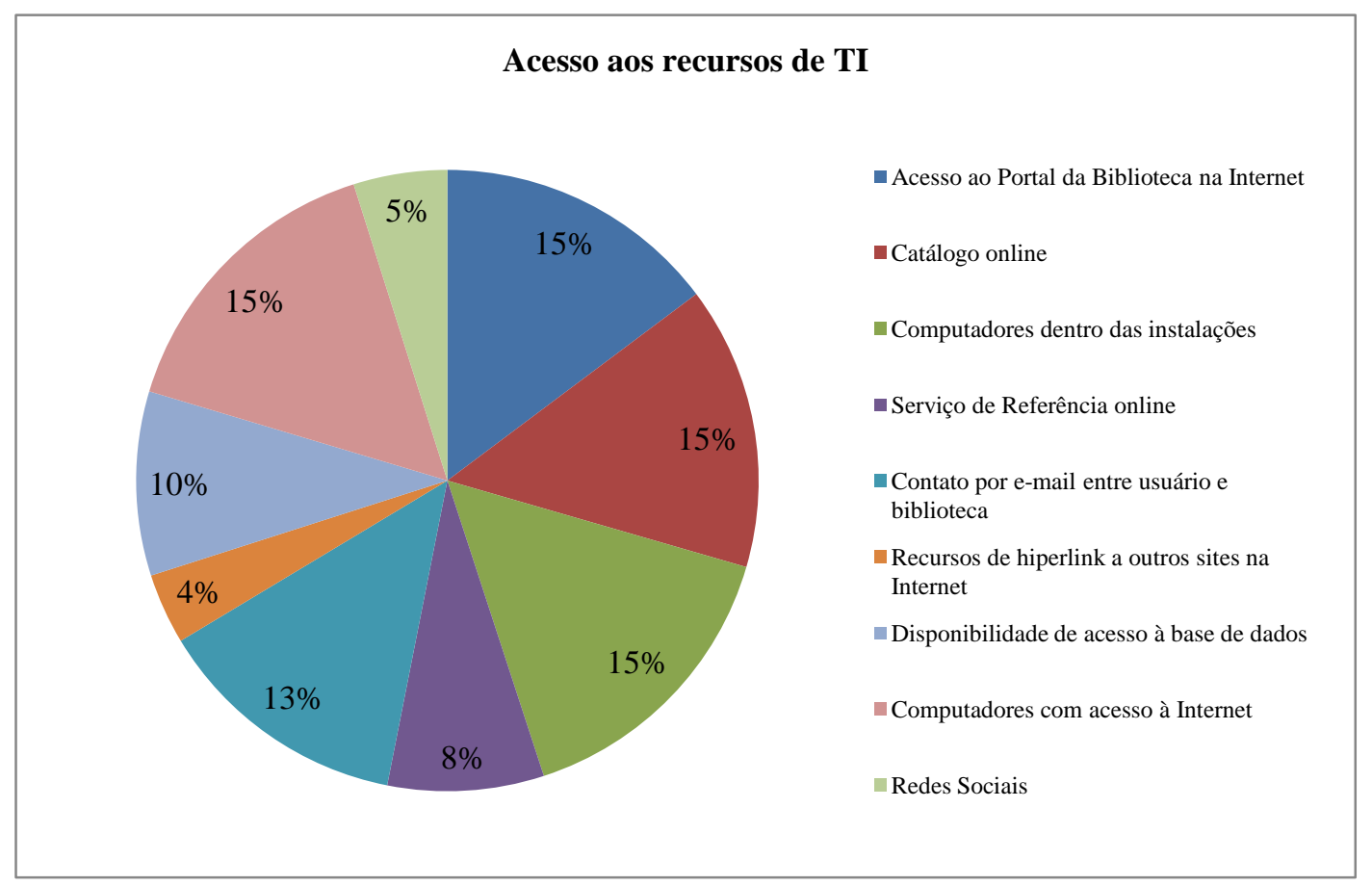

GRÁFICO 2. Acesso aos recursos de TI - Espanha 
Perguntamos como cada biblioteca avalia a política de acesso à informação mediante recursos tecnológicos $9 \%$ apontam que a política de acesso à informação mediada por Tecnologia da Informação (TI) é ruim. Já 14\% apontam que a política de acesso à tecnologia dentro da biblioteca é regular devido às condições de manutenção dos recursos em TI e 64\% que é satisfatória diante de recursos públicos recebidos e da manutenção e atualização dos recursos tecnológicos. E, 13\% afirmam que o acesso é excelente devido aos investimentos em TI avindos de recursos públicos. Conforme demonstramos no Gráfico 3:

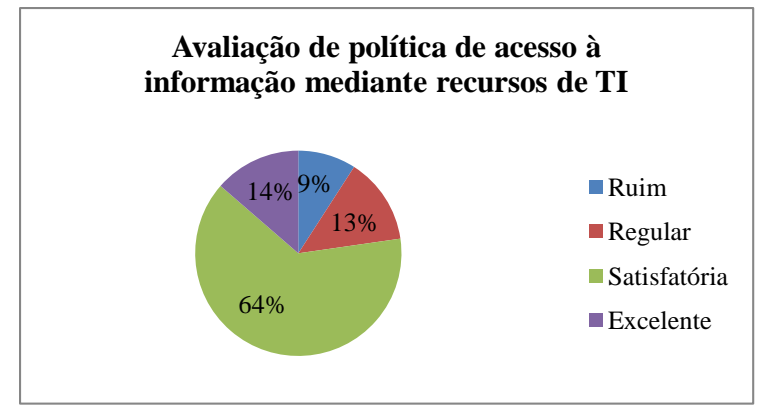

GRÁFICO 3. Política de acesso à informação mediante recursos de TI Espanha

Quanto a cooperação dos provedores de recursos tecnológicos para a biblioteca os respondentes compreendem que são os responsáveis pela gestão dos recursos públicos responsáveis pela transferência de verbas bem como de organizarem a aquisição junto a empresas de tecnologias dos aparelhos e manutenção de sérvios de assistência ao uso de TI.

Conforme o Gráfico 4 demonstra $8 \%$ apontam que a cooperação dos provedores de recursos tecnológicos para a biblioteca é ruim devido aos recursos limitados para as políticas de TI nas bibliotecas e de assistência especializada para sua implantação. Já $46 \%$ indicam que a cooperação é regular e $46 \%$ é satisfatória diante de recursos públicos recebidos. Nenhum dos respondentes atribuiu pontuação para o nível de excelente em relação à provisão dos recursos tanto financeiros quanto de assistência orientado a implantação e manutenção de TI dentro das bibliotecas. 


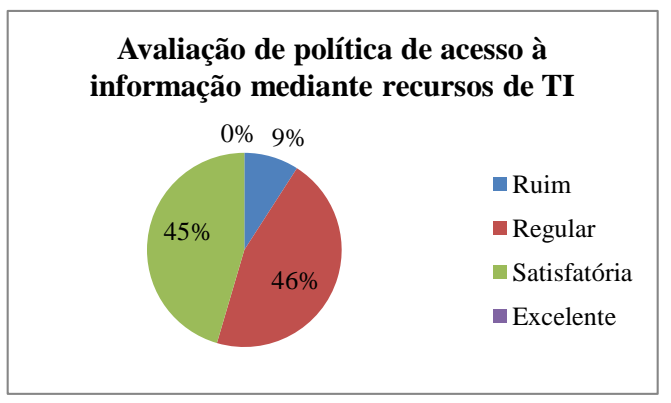

GRÁFICO 4. Política de acesso à informação mediante recursos de TI - Espanha

Ao perguntarmos sobre o que as mídias digitais podem oferecer aos usuários das bibliotecas públicas o discurso recai sobre a globalidade e alcance que a internet oferece às pessoas, ou seja, todo tipo de informação e atualização. Discriminamos os respondentes como BPE 1, BPE 2 e assim sucessivamente, nos depoimentos abaixo, podemos visualizar o discurso em torno da atualização e globalização do alcance das mídias digitais de informação para a biblioteca pública:

BPE 3 - Búsqueda de todo tipo de información. Contactos con las redes sociales.

BPE 13 - Toda la información disponible.

BPE 15 - estar a la última de cualquier información.

BPE 16 -Toda la información disponible.

BPE 17 - Toda la información disponible en la red.

BPE 18 - Acceso rápido, fácil y gratuito a cualquier tipo de información.

BPE 22 - Rapidez, inmediatez, acceso desde cualquier lugar

A ideia de que a internet e as mídias digitais dão o poder de acessar a toda e qualquer informação disponível é uma ideia global em se tratando de bibliotecas públicas. As mídias digitais e a internet de acordo com os depoimentos também possibilitam a interação entre os usuários através do uso das redes sociais, conforme o que diz BPE 17 acima e BPE 4:

BPE 4 - Con el facebook puedo dar información sobre eventos y estimulación a la lectura con presentación de libros 
Ademais, aspectos relacionados a própria concepção de biblioteca carregada em discursos ideológicos de alguns bibliotecários aparece nas falas, como podemos observar em BPE 6:

BPE 6 - Mas dinamismo en la utilizacion de las bibliotecas para que no se queden obsoletas. Comunicacion Internet para uso libre de nuestros usuarios.

Os elementos do pensamento ideológico de que, com o surgimento da internet as bibliotecas poderão tornar-se obsoletas, entendendo que com a incorporação da internet e acesso online aos serviços a biblioteca passa a ser mais dinâmica. Isto não deixa de ser uma verdade, uma vez em que o acesso online aos serviços dá maior fluidez, rapidez e alcance ao acesso aos serviços das bibliotecas públicas, entretanto, traz em seu bojo outras preocupações oriundas da falta de conhecimento do uso das tecnologias. Esta preocupação é clara no discurso de BPE 2 quando aborda a questão da biblioteca pública oferecer serviços que possibilitem, a partir do uso das mídias digitais, oferecer aos usuários estratégias que possam minimizar a exclusão digital.

BPE 2 - Información, referencias y alternativas a la forma tradicional de ofrecer la información, la lectura y la formación, así como la posibilidad de acercar las nuevas tecnologías a sectores más desfavorecidos o que son analfabetos tecnológicos.

O uso da tecnologia e da internet nas bibliotecas públicas da Espanha de acordo com o discurso dos respondentes viabilizam uma maior interação com os usuários, além de formação e entretenimento.

BPE 20 - Información, posibilidad de interactuar con la biblioteca, realizar consultas, obtener información, descargar documentos.

BPE 21 - Información, formación, entretenimiento

Todo discurso traz em seu arcabouço um interdiscurso (FOUCAULT, 2005), o que nos ajuda a pensar que o pensamento sobre o uso das tecnologias nas bibliotecas públicas em Espanha carrega elementos encrustados em discursos profissionais da atualidade e cabe para qualquer país. O que significa que ao apresentarmos as tecnologias digitais de informação como necessárias ao bom andamento dos serviços das bibliotecas públicas, a colocamos concomitantemente na atualidade que a própria tecnologia exige. 
Ao perguntarmos sobre a contribuição da biblioteca para a democratização do acesso à informação através das tecnologias disponíveis, os respondentes afirmam quase unanimemente que se dá a partir do acesso livre e gratuito, conforme observamos abaixo:

BPE 1 - Acceso libre y gratuito.

BPE 3 - Todos los usuarios tienen disponibilidad gratuita para la utilización de la tecnología dentro de la sala, también con portatiles personales u otras herramientas mediante wifi.

BPE 7 - Para que esa información sea más accesible y esté al alcance cada vez más del mayor número de personas de todas las condiciones y orígenes. Los ordenadores son de libre acceso, sólo tiene el interesado que tener la tarjeta de usuario de la Red de Bibliotecas. El uso es totalmente gratuito.

BPE 11 - El acceso es libre y gratuito con lo que se contribuye a la democratización de la sociedad y a los medios de información a través de internet. La posibilidad de conectarse a Internet gratuitamente contribuye a nivelar las desigualdades económicas.

BPE 13 - Acceso libre y gratuito a cualquier medio digital

BPE 14 - Pues siendo democrática, es decir, todo el mundo que venga a la biblioteca tiene derecho a usar las tecnologías disponibles en esta.

BPE 15 - Disponemos de un servicio para el usuario gratuito

BPE 16 - Acceso libre y gratuito a cualquier medio digital

BPE 17 - Acceso libre y gratuito a cualquier medio digital disponible en la red

BPE 19 - Acceso universal sin ningún tipo de discriminación

Ao analisarmos as respostas a partir do discurso ideológico traçamos a intrínseca relação entre a palavra democratização e acesso, entretanto, ressaltamos que os respondentes fizeram outras relações possíveis. Estabeleceram conexões como a democratização da sociedade a partir do acesso livre a informação contribuindo para diminuir as desigualdades econômicas (BPE 11). Entendemos que democratização e acesso à informação estão relacionadas ideologicamente neste contexto pela possibilidade de viabilizar um acesso abrangente, dinâmico e universal a toda e qualquer informação.

\subsection{Acesso à Informação em Bibliotecas Públicas da Alemanha}

Sobre a adequação de acesso à tecnologia nas bibliotecas públicas da Alemanha, o resultado, conforme apresentamos no Gráfico 5, para $49 \%$ o acesso à tecnologia na biblioteca é ruim e 51\% apontam que o acesso é regular, prejudicado 
principalmente pela falta de assistência tecnológica e investimentos com recursos públicos adequados. Nenhum dos respondentes aponta que o acesso à tecnologia na biblioteca é satisfatório ou excelente.

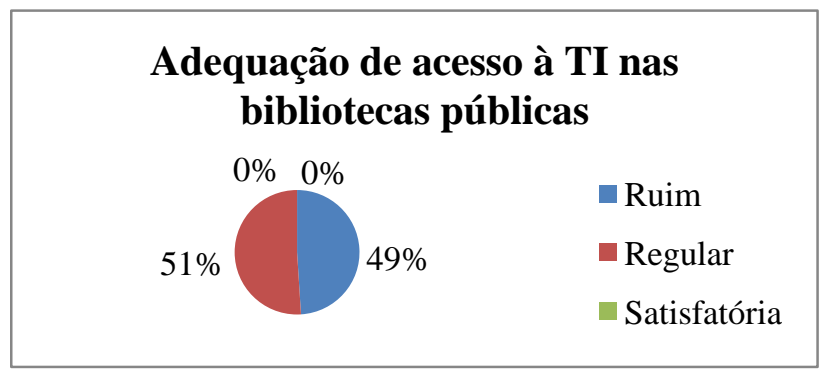

GRÁFICO 5. Adequação de acesso à tecnologia nas bibliotecas públicas - Alemanha

Quanto aos recursos tecnológicos oferecidos aos usuários das bibliotecas públicas alemãs, 100\% de bibliotecas possuem tecnologias de informação. Desse total, todos os respondentes apontam que possuem portal da biblioteca disponível na Internet, computadores incluindo acesso à Internet para os usuários. Os serviços relacionados com a localização dos acervos como o catálogo online são de 100\%. Já os serviços de contato e mediação da informação se manifestam pelo oferecimento de: nenhum oferece Serviço de Referência online, todavia, $100 \%$ oferecem atendimento de informação via e-mail. Já os recursos de acesso às fontes externas de informação como acesso aos hiperlinks e bases de dados somam 50\% e $100 \%$ respectivamente. De acordo com os respondentes, somente $15 \%$ das unidades oferecem acesso às redes sociais na Internet. Para melhor visualizarmos os dados estão discriminados no Gráfico 6: 


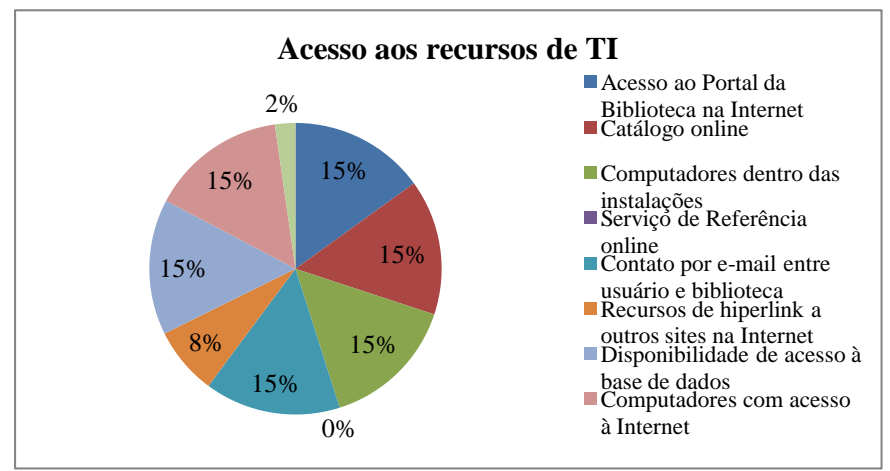

GRÁFICO 6. Acesso aos recursos de TI - Alemanha

A avaliação da política de acesso à informação mediante os recursos tecnológicos pelos respondentes aponta que 9\% é ruim. Entretanto, 37\% afirmam que é regular devido às condições de manutenção dos recursos em tecnologias, através de fundo públicos do Estado onde as bibliotecas estão situadas. Já 54\% apontam que a política de acesso à tecnologia na biblioteca é satisfatória diante de recursos públicos recebidos e de manutenção da atualização dos recursos tecnológicos através de fundos públicos advindos dos municípios onde estão as bibliotecas estão inseridas. Nenhum respondente acredita que a política de acesso à informação mediante recursos tecnológicos é ruim ou excelente. Conforme podemos visualizar no Gráfico 7:

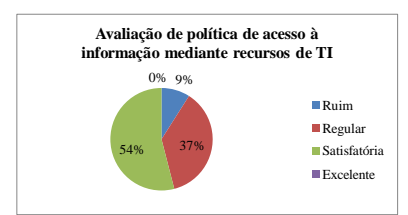

GRÁFICO 7. Política de acesso à informação mediante recursos de TI Alemanha

Quanto a cooperação dos provedores de recursos tecnológicos para a biblioteca pública na Alemanha, os respondentes compreendem que são os 
responsáveis pela gestão dos recursos públicos responsáveis pela transferência de verbas bem como de organizarem a aquisição junto a empresas de tecnologias dos aparelhos e manutenção de sérvios de assistência ao uso de TI. Para 50\% dos respondentes a cooperação dos provedores de recursos tecnológicos para a biblioteca é regular. E a outra metade afirma que é satisfatória por atender às necessidades da biblioteca em termos de serviços baseados em tecnologia. Nenhum dos respondentes, porém, atribuiu nível ruim ou excelente à este quesito.

A importância do uso das mídias digitais pelas bibliotecas públicas na Alemanha traz no discurso dos respondentes a importância do acesso à informação, garantindo uma amplitude dos serviços da biblioteca e uma preocupação com os custos dessas tecnologias, conforme observamos nas falas abaixo:

BPA 1 - O acesso a serviços fora de sua coleção própria biblioteca. Se possível, o acesso simultâneo por várias pessoas o acesso a bases de dados, etc fora do horário de funcionamento da biblioteca, se disponível online.

BPA 2 - Importante para o desenvolvimento da sociedade, embora os custos ainda sejam muito caros.

Sobre a participação da biblioteca na democratização do acesso à informação, os respondentes afirmam que o compromisso com o trabalho, a seriedade e garantem que há investimentos públicos para oportunizar os usuários das bibliotecas públicas acesso à informação, conforme observamos nos depoimentos abaixo:

BPA 1 - Tal como um banco, estamos comprometidos para o uso generalizado dos meios de informação nas bibliotecas em nossa área de trabalho, para permitir, especialmente em bibliotecas fora das grandes cidades e áreas metropolitanas de informações e transferência de conhecimento.

BPA 2 - A democratização da informação tem um preço incalculável, na Alemanha isso não representa um problema social devido aos investimentos e políticas de informação que incluem bibliotecas públicas.

Como a 'Bibliothek \& Information Deutschland' (2011) aponta, a cada ano uma nova biblioteca pública e uma biblioteca escolar nascem na Alemanha. A maioria das bibliotecas públicas é organizada pelos municípios. A biblioteca pública municipal pode servir como seu próprio departamento ou como uma entidade cuja responsabilidade é dividida com a secretaria de educação e cultura. Muitos 
municípios já começaram a separar certas instituições municipais de governo central, dando-lhes a forma de sociedades autônomas geridas de acordo com critérios comerciais. Esta nova forma de organização também foi aplicada para as várias bibliotecas de porte médio e grande. $\mathrm{Na}$ frente dessas empresas há uma comissão administrativa, que também faz parte geralmente de vereadores e comunidades de usuários (SEEFELDT; SYRE, 2007).

\subsection{Acesso à informação em Bibliotecas Públicas do Brasil}

A adequação do acesso às tecnologias da informação nas bibliotecas públicas no Brasil conforme discriminado no Gráfico 8 é regular para $49 \%$ dos respondentes, já 32\% apontam que o acesso é ruim, prejudicado pela falta de assistência tecnológica e investimentos com recursos públicos. Para 13\% o acesso à tecnologia é satisfatório e apenas $6 \%$ afirmam que é excelente.

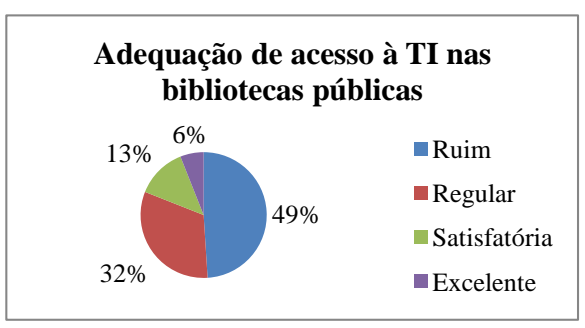

GRÁFICO 8. Adequação de acesso à tecnologia nas biblio tecas públicas - Brasil

A respeito dos recursos tecnológicos oferecidos pela biblioteca pública aos usuários os respondentes apontam que $38 \%$ de bibliotecas não possuem TI. As unidades que oferecem serviços baseados em TI em suas instalações apontam que possuem computadores em suas instalações $(69,7 \%)$ e destes $66,7 \%$ oferecem ao usuário acesso à Internet. Os serviços relacionados com a localização dos acervos como o catálogo online são de 15,2\%. Já os serviços de contato e mediação da informação se manifestam pelo oferecimento de: Serviço de Referência online (3\%) bem como desenvolvem acesso à biblioteca através de portal na Internet $(18,2 \%)$, contato através de e-mail $(36,4 \%)$. Já os recursos de acesso às fontes externas de 
informação como acesso aos hiperlinks e bases de dados somam 6,1\% cada. De acordo com os respondentes, não há acesso às redes sociais na Internet.

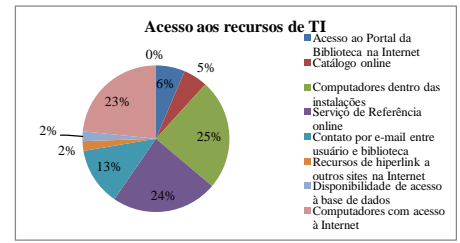

GRÁFICO 9. Acesso aos recursos de TI - Brasil

A política de acesso à informação mediada por recursos tecnológicos nas bibliotecas públicas é avaliada pelos respondentes como ruim por $28 \%$ e como regular por $49 \%$, reiterando que essa avaliação é decorrente da falta de assistência tecnológica e investimentos com recursos públicos apontadas na questão anterior. Já $15 \%$ apontam que a política de acesso à tecnologia na biblioteca é satisfatória diante de recursos públicos recebidos. E apenas $8 \%$ afirmam que é excelente devido aos investimentos em tecnologia com recursos públicos, conforme podemos visualizar no Gráfico 10:

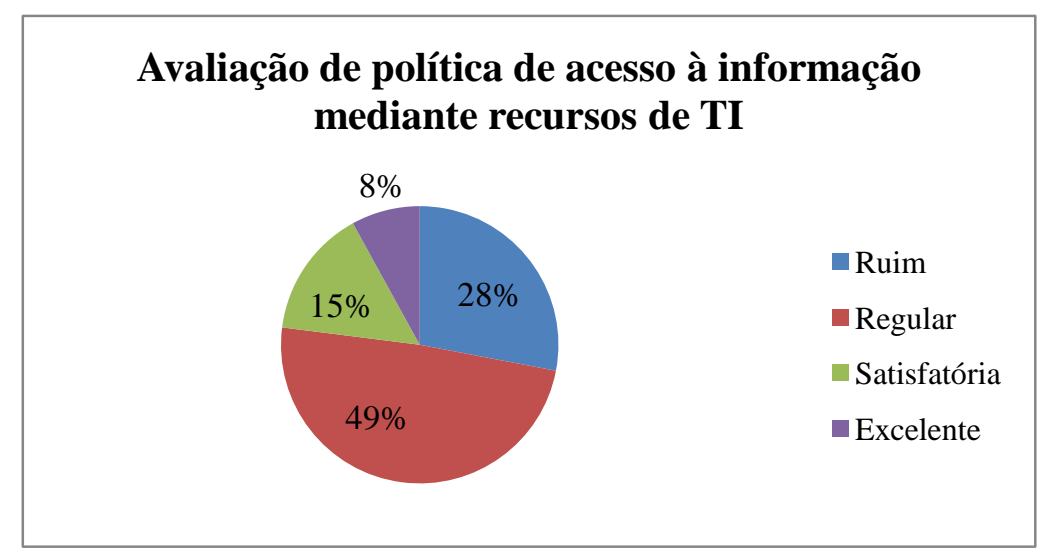

GRÁFICO 10. Política de acesso à informação mediante recursos de TI Brasil 
Por provedores de recursos tecnológicos, os respondentes compreendem que são os responsáveis pela gestão dos recursos públicos responsáveis pela transferência de verbas bem como de organizarem a aquisição junto a empresas de tecnologias dos aparelhos e manutenção de sérvios de assistência ao uso de tecnologia. Conforme demonstra o gráfico 11 para $43 \%$ dos respondestes a cooperação dos provedores de recursos tecnológicos para a biblioteca é ruim devido aos recursos limitados para as políticas de tecnologia nas bibliotecas e de assistência especializada para sua implantação. Enquanto 43\% apontam que a cooperação é regular, reiterando que essa avaliação é decorrente da falta de assistência tecnológica e investimentos com recursos públicos apontadas nas questões anteriores. E $11 \%$ avaliam que a cooperação de provedores de tecnologia é satisfatória diante de recursos públicos recebidos. E apenas $2 \%$ afirmam que a cooperação atinge um nível de excelência em relação à provisão dos recursos tanto financeiros quanto de assistência orientados a implantação e manutenção de tecnologias de informação dentro das bibliotecas.

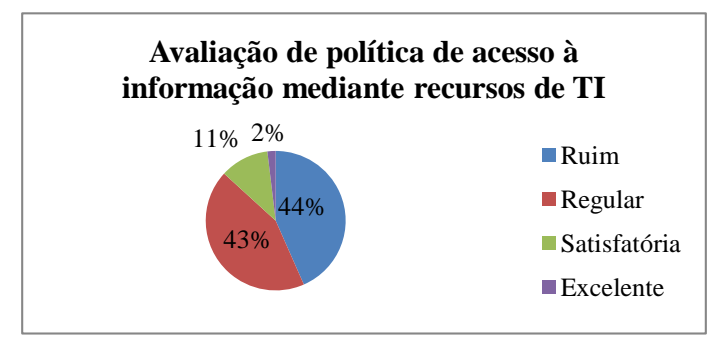

GRÁFICO 11. Política de acesso à informação mediante recursos de TI

O discurso sobre as mídias digitais dos respondentes das bibliotecas públicas brasileiras reforçam a compreensão que as tecnologias proporcionam maior rapidez e facilitam o acesso à informação, conforme observamos nas falas abaixo:

BPB 4 - Muitas informações sobre todas as áreas, as quais chegam com mais facilidade e rapidez aos os usuários.

BPB 5 - Rapidez e facilidade para a informação.

BPB 6 - Acesso fácil e rápida informação, além de alto nível de sites educativos que podem proporcionar lazer, conhecimento e segurança. 
BPB 18 - as mídias facilitam a pesquisa e faz com que os usuários ganhem tempo. Com acesso aos sites de busca o s alunos ganham possibilidades de ampliar seu link de informações

BPB 21 - Maior acesso as informações e o conhecimento em tempo hábil e com variedade

BPB 22 - Maior acesso aos conhecimentos.

BPB 29 - Novos conhecimentos, novas informações, maior facilidade de acesso ao conhecimento.

BPB 34 - divulgação e facilidade.

BPB 35 - Uma informação mais rápida, diversa e com mais comodidade.

BPB 43 - Proporciona pesquisas mais rápidas, não havendo necessidade consulta a livros. No que diz respeito a usuário de nível superior, pois a biblioteca dispõe de poucos livros voltados pra esse nível.

Quanto à contribuição da biblioteca pública brasileira para a democratização da informação mediante o uso de tecnologia é ínfima, uma vez em que a maioria das bibliotecas não dispõe de tecnologias ou é insuficiente para o uso da clientela. Este resultado se contrapõe ao discurso anterior quanto a importância do uso das tecnologias da informação e comunicação e colocam as bibliotecas públicas do Brasil em situação de alerta. Conforme podemos observar nas falas dos respondentes as bibliotecas públicas brasileiras além da falta de equipamentos tecnológicos há também insuficiência de profissionais com competência tecnológica e informacional para realizar os serviços:

BPB 3 - A contribuição para democratização mediante uso da tecnologia é precário, pois não dispomos de servidores capacitados para mediação do processo de utilização de novas tecnologias inseridos no contexto da biblioteca pública municipal.

BPB 6 - Contribui muito pouco, pois não possui aparelhos tecnológicos em quantidade suficiente.

BPB 8 - Contribui muito pouco

BPB 21 - Acredito que contribua parcialmente, uma vez que o acesso dos usuários ainda é muito tímido, ou seja não há um fluxo de frequência/visitas grande por parte dos usuários.

BPB 25 - Contribui ainda de modo insatisfatório por conta do número de computadores disponível na biblioteca.

BPB 26 - Não contribui de maneira alguma, uma vez que só possuímos um computador ligado a internet, mas somente para o uso dos funcionários.

BPB 27 - Não contribui, pelo fato de não possuir computadores.

BPB 28 - Não, porque não temos o uso da tecnologia disponível ao usuário no momento e esperamos mudar essa visão para que venha 
acontecer em municípios menores a possibilidade de adequar a tecnologia no mundo dos livros.

Enquanto na Espanha as bibliotecas públicas dispõem de computadores para uso da clientela e acesso a rede wifi em quase toda a Red de Bibliotecas Públicas e na Alemanha a biblioteca ser encarada como um banco e dispor de políticas públicas e investimento para a democratização do acesso à informação, no Brasil o acesso é precário devido a falta de computadores e pessoal qualificado. $\mathrm{O}$ discurso dos respondentes refletem a insatisfação no que diz respeito às políticas públicas para as bibliotecas e denunciam que para se pensar em acesso democrático, livre e gratuito à informação é necessário dotar as bibliotecas públicas de equipamentos tecnológicos de qualidade e oportunizar a qualificação profissional dos funcionários.

\section{CONSIDERAÇÕES FINAIS}

Ao analisarmos as respostas a partir do discurso ideológico traçamos a intrínseca relação entre a palavra democratização e acesso, entretanto, ressaltamos que os respondentes fizeram outras relações possíveis. Estabeleceram conexões como a democratização da sociedade a partir do acesso livre a informação contribuindo para diminuir as desigualdades sociais. Entendemos que democratização e acesso à informação estão relacionadas ideologicamente neste contexto pela possibilidade de viabilizar um acesso abrangente, dinâmico e universal a toda e qualquer informação. É o que Cunha (2003) assinala sobre a missão especial da biblioteca pública de assegurar a democratização do acesso à informação em rede.

A Bibliothek \& Information Deutschland (2011) afirma que a cada ano uma nova biblioteca pública e uma biblioteca escolar nascem na Alemanha. A maioria das bibliotecas públicas é organizada pelos municípios. A biblioteca pública municipal pode servir como seu próprio departamento ou como uma entidade cuja responsabilidade é dividida com a secretaria de educação e cultura. Muitos municípios já começaram a separar certas instituições municipais de governo central, dando-lhes a forma de sociedades autônomas geridas de acordo com critérios comerciais. Esta nova forma de organização também foi aplicada para as várias bibliotecas de porte médio e grande. 


\section{REFERÊNCIAS}

BERNARDINO, Maria Cleide Rodrigues; SUAIDEN, Emir José. O papel social da biblioteca pública na interação entre informação e conhecimento no contexto da ciência da informação. Perspectivas em ciência da informação, v. 16, n. 4, p. 29-41, 2011. Disponível em: $<$ http://portaldeperiodicos.eci.ufmg.br/index.php/pci/article/view/1257/970>. Acesso em: 7 set. 2012.

\section{BIBLIOTHEK \& INFORMATION DEUTSCHLAND. Medien- und Informationskompetenz - immer mit Bibliotheken und informationseinrichtungen! Berlin: BID, 2011. Disponível em: <http://www.bideutschland.de/download/file/Medien- \%20und\%20Informationskompetenz.pdf>. Acesso em: 9 maio 2012.}

CAVALCANTE, Lidia Eugênia. Cultura informacional e gestão de bibliotecas públicas municipais: competências e usos da informação. In: ENCONTRO NACIONAL DE PESQUISA EM CIÊNCIA DA INFORMAÇÃ̃O, 11., 2010, Rio de Janeiro. Anais... Rio de Janeiro, ANCIB, 2010. Disponível em: <http://congresso.ibict.br/index.php/enancib/xienancib/paper/view/128/252>. Acesso em: 7 set. 2012.

CUEVAS-CERVERÓ, Aurora. Formación de la ciudadanía en entornos de información electrónica: alfabetización informacional. In: VIVES, Josep. (Coord.) Digitalización del património: archivos, bibliotecas y museos en la red. Barcelona: Editorial UOC, 2009.

CUNHA, Vanda Angélica da; Damasceno, Elane Conceição; Santos, Levi Alã Neves dos; Vasconcelos, Jandira dos Santos Reis. Biblioteca pública, desafios, perspectivas e (des) caminhos na inclusão digital. In: ENCONTRO NACIONAL DE ENSINO E PESQUISA EM INFORMAÇÃO, 6., 2005, Salvador. Anais... Salvador, UFBA, 2005. Disponível em: <http://www.cinform-anteriores.ufba.br/vi_anais/docs/VandaElaneLeviJandira.pdf $>$. Acesso em: 7 set. 2012.

CUNHA, Vanda Angélica da. A biblioteca pública no cenário da sociedade da informação. Biblos, año 4, n. 15, abr./jun., p.67-76, 2003. Disponível em: <http://dialnet.unirioja.es/servlet/articulo?codigo=743225>. Acesso em: 7 set. 2012.

DÍAZ SÁNCHEZ, Marlery. Las competencias desde la perspectiva informacional: apuntes introductorios a nivel terminológico y conceptual, escenarios e iniciativas. Ciência da Informação, Brasília, v.37, n.1. p.107-120, 2008. Disponível em:

<http://revista.ibict.br/ciinf/index.php/ciinf/article/view/935>. Acesso em: 13 out. 2012.

FELICIÉ SOTO, Ada Myriam. Biblioteca pública, sociedade de la información y brecha digital. Buenos Aires: Alfagrama, 2006.

FOUCAULT, Michel. A arqueologia do saber. Rio de Janeiro: Forense Universitária, 2005.

GIL, Antônio Carlos. Métodos e técnicas de pesquisa social. São Paulo: Atlas, 1999.

INTERNATIONAL FEDERATION OF LIBRARY ASSOCIATIONS; UNITED NATION EDUCATIONAL . Manifesto da IFLA/UNESCO sobre bibliotecas públicas. 1994. Disponível em: <http://archive.ifla.org/VII/s8/unesco/port.htm>. Acesso em: 7 set. 2012.

JARAMILLO, Orlanda; MONTOYA RIOS, Mônica; URIBE TIRALDO, Alejandro. La biblioteca pública y su gestión: en el contexto de la sociedade de la información. Buenos Aires: Alfagrama, 2008.

LANKES, R. David. The atlas of new librarianship. Cambridge: The MIT Press, 2011.

LOZANO DÍAZ, Roser. La biblioteca pública del siglo XXI: atendendo clientes, movilizando personas. Asturias: Ediciones Trea, 2006. 
MINAYO, Maria Cecília de Souza. (Org.) Pesquisa social: teoria, método e criatividade. Rio de Janeiro: Vozes, 2008.

PÊCHEUX, Michel. Semântica e discurso: uma crítica à afirmação do óbvio. Campinas: UNICAMP, 1995.

SEEFELDT, Jürgen; SYRÉ, Ludger. Portais de acesso ao passado e ao futuro: as bibliotecas alemãs. Hildesheim: Georg Olms Verlag, 2007.

SUAIDEN, Emir José. El impacto social de las bibliotecas públicas. Anales de Documentación, n. 5, p. 333-344, 2002. Disponível em:

<http://repositorio.bce.unb.br/handle/10482/584>. Acesso em: 7 set. 2012.

. Biblioteca pública no contexto da sociedade da informação. Ciência da Informação, Brasília, v. 29, n. 2, p.52-60, 2000. Disponível em:

<http://www.scielo.br/pdf/ci/v29n2/a07v29n2.pdf >. Acesso em: 7 set. 2012.

\section{Como citar este artigo:}

BERNARDINO, Maria Cleide Rodrigues; ALENTEJO, Eduardo da Silva. Perfil tecnológico das bibliotecas públicas no brasil e na europa: estudo sobre a democratização do acesso a informação e ao conhecimento em bibliotecas do brasil, espanha e alemana Rev. digit. bibliotecon. cienc. inf., Campinas, SP, v. 11, n. 3, p.46-71, maio/ago. 2013. ISSN 1678-765X. Disponível em: <http://www.sbu.unicamp.br/seer/ojs/index.php/rbci> 